\title{
Bidding BeHAVIOR AND DeCision COSTS In FiELd ExPERIMENTS
}

\author{
by
}

John A. List and David Lucking-Reiley

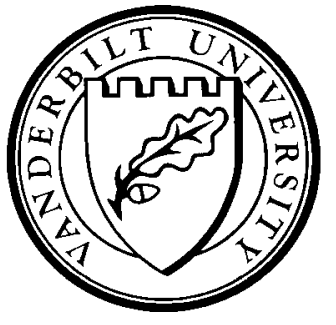

Working Paper No. 00-W06

March 2000

\section{DEPARTMENT OF ECONOMICS \\ VANDERBILT UNIVERSITY \\ NASHVILLE, TN 37235}

www.vanderbilt.edu/econ 


\title{
Bidding Behavior and Decision Costs in Field Experiments
}

\author{
John A. List and David Lucking-Reiley*
}

12 March 2000

\begin{abstract}
Whether rationality of economic behavior increases with expected payoffs and decreases with the cognitive cost it takes to formulate an optimal strategy remains an open question. We explore these issues with field data, using individual bids from sealed-bid auctions in which we sold nearly $\$ 10,000$ worth of sportscards. Our results indicate that stakes do indeed matter, as high-priced (\$70) cards produced more of the theoretically predicted strategic behavior than did lower-priced (\$3) cards. We find additional evidence consistent with the importance of cognitive costs, as subjects more experienced with sportscard auctions exhibited a greater tendency to behave strategically than did less experienced bidders.
\end{abstract}

JEL: D44 (Auctions), C93 (Field Experiments), Keywords: Cognitive Cost, Multi-Unit Auctions, Field Experiments

*List: Department of Economics, University of Central Florida, Orlando, FL 32765, john.list@bus.ucf.edu

Lucking-Reiley: Department of Economics, Vanderbilt University, Nashville, TN 37235, reiley@vanderbilt.edu. 


\section{Introduction}

Positive opportunity costs of mental effort may invalidate the predictions of traditional models of rational (or hyper-rational) agents. Conlisk (1996) uses deliberation costs as a recurring theme when discussing four important reasons for incorporating bounded rationality in economic models. Smith and Walker (1993) and Smith and Szidarovszky (1999) present effort models which predict that individuals' behavior will more closely match the predictions of rational-behavior theories as (1) the stakes of the decision increase, and (2) the decision costs decrease. ${ }^{1}$ Smith and Walker (1993) find evidence of these two effects in a comprehensive review of thirty-one published laboratory experiments. Camerer and Hogarth (1999) extend Smith and Walker's survey by examining 74 experimental papers, and find evidence in favor of the cognitive-effort theory, noting that "higher levels of incentives have the largest effects in judgment and decision tasks." Although the laboratory evidence is compelling, there has been little verification of these predictions outside the laboratory. ${ }^{2}$

The present paper fills this gap by examining field data from 164 multi-unit sportscard auctions carried out on the floor of a sportscard show. We auctioned four types of trading cards with book values ranging from $\$ 3$ to $\$ 70$, providing significant variation in the stakes of the auction. Our auctions also included two distinct types of subjects: some auctions had sportscard dealers bidding against each other, while others had individual card collectors as the participants. This variation allows us to explore the

\footnotetext{
${ }^{1}$ Whereas Smith and Walker (1993) model man versus nature, Smith and Szidarovszky (1999) extend the model to allow for interactive decision in the n-person case.

2 Note, however, the similarities of increasing rewards with the parallel literature that compares hypothetical and real responses (see, e.g., List and Shogren, 1998, and List, 2000).
} 
second dimension of decision-cost theory-do dealers, who commonly participate in sportscard auctions and therefore likely require less effort to bid optimally, bid more rationally than nondealers? Our measure of "rational" bidding comes from multi-unit auction theory, which predicts strategic "demand reduction" in uniform-price auctions. For each type of bidder and each type of card, we measure this demand-reduction behavior in the uniform-price auction relative to a control (the multi-unit Vickrey auction) where bidders are predicted to fully reveal their demands.

Our sportscard data, generated from sales of 328 sportscards with a combined book value of nearly $\$ 10,000$, provide two major insights. First, we find that the predicted strategic behavior is considerably greater when the auctioned sportscards have higher values. Second, dealers exhibit more of the predicted strategic behavior than do nondealers, for both lower and higher priced cards. Nondealers may find that the cognitive effort required to bid strategically exceeds the benefits, especially for lowvalued cards. By contrast, dealers have more experience with auctions and make their living by trading cards, so their cognitive costs are likely lower than those of nondealers. These two findings are consistent with recent theoretical models of monetary rewards and decision costs, and extend previous experimental evidence from the laboratory into the field.

\section{Background on Multi-Unit Auctions}

Our experiment examines bidding behavior in sealed-bid auctions for two identical units of a homogeneous good, using two different price rules: uniform-price and generalized Vickrey. A recent wave of theoretical literature has investigated equilibria in 
uniform-price auctions with multi-unit demand (Noussair (1995), Katzman (1995), Tenorio (1997), Engelbrecht-Wiggans and Kahn (1998), and Ausubel and Cramton (1997)). The main result is that in uniform-price auctions, bidders have a dominant strategy to truthfully reveal their demands for the first unit of the good, but they have an incentive to reduce their bids below their valuations for additional units. The incentive is that one's bid on an additional unit might end up determining the price paid for winning a single unit, so a lower bid has some chance of increasing one's consumer surplus. ${ }^{3}$ The economic consequences of demand reduction include inefficient allocations and possible reductions in auction revenue.

To avoid the inefficiencies associated with the uniform-price auction, theorists have identified an alternative mechanism, the generalized Vickrey auction, which gives bidders a dominant strategy of revealing their true valuations for all units of the good. In this multi-unit Vickrey auction, as in the uniform-price auction, each bidder can submit up to $\mathrm{n}$ different sealed bids on individual units, and the top $\mathrm{n}$ bids are declared winners. If a bidder submits one or more of the winning bids, her price for her first unit equals the highest rejected bid submitted by someone else, and her price for the kth unit equals the

\footnotetext{
3 As Engelbrecht-Wiggans and Kahn (1998) demonstrate, multiple equilibria are possible, including equilibria which involve truthtelling on both units. However, Ausubel and Cramton (1996) demonstrate that truthtelling equilibria are a special case; in almost all bidder valuation environments, a Nash equilibrium is guaranteed to have some demand reduction.
} 
kth highest of the rejected bids submitted by others. ${ }^{4}$ This is a special case of a GrovesClarke mechanism for dominant-strategy truthtelling. ${ }^{5}$

For our purposes, this auction literature provides predictions about strategic behavior on which to base a test of cognitive costs and rewards. Theory predicts secondunit bids to be lower in the uniform-price auction than in the Vickrey auction. If deliberation costs are important, we should find that demand reduction in the uniformprice auctions is more prevalent for higher priced cards, as bidders will tend to invest more effort in thinking about the subtle strategic incentives when they stand to gain more from such effort. We have a similar prediction about dealers versus nondealers. Dealers routinely participate in sportscard auctions both to sell and acquire their card stocks, and even though they may never have participated in these particular auction formats, they may exert less cognitive effort to find optimal strategies than nondealers with less prior auction experience of any kind. Since dealers make their living selling cards and typically sell cards for higher prices than nondealers, the monetary rewards to strategic behavior may also be much larger for dealers. Both effects predict more strategic demand reduction for dealers than nondealers.

\section{Data}

\footnotetext{
${ }^{4}$ Technically, these rules are demand-revealing only in cases where every bidder's demand curve is either flat or downward-sloping, as is assumed in the theoretical papers cited above. If bidders have upwardsloping demands (increasing returns to scale in purchases), then this simple pricing rule is invalid; a slightly more complicated set of instructions would be required to implement a Groves-Clarke truthtelling mechanism.

${ }^{5}$ See Groves(1973) and Clarke(1971). Intuitively, the key feature of this mechanism is that when bidders truthfully reveal their willingness to pay for the goods, the price rule ensures that each winning bidder pays an amount equal to the surplus she displaces from the other bidder(s) who would have won in her absence.
} 
We use data from a field experiment at a 1998 Orlando trading card show (List and Lucking-Reiley (2000)) to compare outcomes in uniform-price and Vickrey sealedbid auctions, with particular attention paid to the effects of rewards and deliberation costs. We conducted 82 Vickrey and 82 uniform-price auctions. Our participants were of two types: card dealers and nondealers, each bidding against rivals of the same type. The auctioned sportscards fit into two price categories: low (book value of \$3) and high (book value of \$70). For the low-priced card auctions, we chose a Joe Montana 1982 Topps football card and a 1989 Michael Jordan Hoops basketball card. For the higherpriced auctions, we selected a Cal Ripken, Jr. 1982 Topps baseball card and a Barry Sanders 1989 Score football card. We sold dozens of each type of card, with all cards in identical condition. All auctions for a given card type displayed the same sportscards to bidders, and identical copies were sold to winning bidders after the auctions concluded.

To perform the simplest possible field experiment, we chose a design with two bidders and two cards per auction. Two bidders were invited to submit two bids each for two identical sportscards, in an auction with no reserve price. We chose the auction format and card type for each subject according to a predetermined schedule, to avoid accidentally introducing experimenter bias. After receipt of bids from a group of subjects within a treatment, we randomly matched pairs of bidders to determine the outcome of each two-person auction. Each participant's experience typically followed four steps: (1) inspection of the good, (2) learning the auction rules, (3) placing two bids, and (4) conclusion of the transaction (usually a couple of hours after step (3)). No subject participated in more than one auction. ${ }^{6}$

\footnotetext{
${ }^{6}$ Experimental instructions are in the Appendices. For more details about the experimental procedure, see List and Lucking-Reiley (2000).
} 
Table 1 provides a breakdown of the number of auctions completed. In total, we ran 164 different two-unit auctions, including 82 uniform-price and 82 Vickrey. We auctioned 328 sportscards with a total book value of nearly $\$ 10,000$. The numbers in the table represent the number of auctions run for each treatment type. For example, we ran 15 uniform-price dealer auctions for Cal Ripken Jr. cards, which implies that we sold 30 Cal Ripken, Jr. cards to dealers in uniform-price auctions.

\section{Experimental Results}

Table 2 presents descriptive statistics of our bidding data. In List and LuckingReiley (2000), we noted that the data provide evidence of strategic demand reduction-across all five treatments second-unit bids are lower in the uniform-price auctions than in the Vickrey auctions. Here, we push the data somewhat harder, and note that the amount of demand reduction appears to vary both with the stakes of the experiment ( $\$ 3$ versus $\$ 70$ book values) and with the level of bidder experience (nondealers versus dealers).

Before comparing the strategic behavior across dealers and nondealers, we point out two apparent differences in their underlying demands for cards. First, dealers' demands tend to be situated at a higher level than those of nondealers for the Joe Montana card (book value \$3), which was the only card auctioned to both types of bidders. In both Vickrey and uniform-price auctions, and for both first units and second units of the good, mean bids are higher for dealers than for nondealers. Second, dealers'

demands also appear to be less steeply sloped. In the Vickrey auction, where bids should 
equal bidders' true values, we find that dealers value a second unit at $\$ 0.77$ (or 38\%) less than a first unit, on average, while the corresponding decline for nondealers is significantly larger, at $\$ 0.90$ (or $66 \%$ ). This second effect also appears in the data for $\$ 70$ cards, though the comparison is less clean because the cards auctioned to the two groups were not identical. First-unit bids on $\$ 70$ cards are relatively similar across subject types, but demands are again less steeply sloped for dealers than for nondealers. The mean decline between first and second Vickrey auction bids is $\$ 7.83(16 \%)$ for dealers, but $\$ 23.00(44 \%)$ for nondealers.

The differences across bidder types appear consistent with dealers having better resale opportunities for cards. Dealers hold inventories of cards that they later sell to individual consumers typically at flat prices-they can usually sell a second copy of a single card at the same price as they sold the first. Dealers also buy cards from individual consumers, typically at prices $40-60 \%$ lower than those at which they sell them. By contrast, most consumers collect single copies of individual cards, with little interest in holding multiple copies. Furthermore, a given sportscard consumer might not even desire a single copy of a particular card (e.g., if she already has a copy, or if she does not collect cards of that type). For cards not desired for their collections, nondealers' resale opportunities are much lower than the resale opportunities of dealers. Nondealers might be expected to get lower prices when selling, and would also generally find it more inconvenient (costly) to locate a buyer. ${ }^{7}$ Overall, then, we might expect individual

\footnotetext{
${ }^{7}$ This inconvenience might be relatively large in the case where the consumer wants to resell a single lowvalued card, which helps to depress nondealers' values proportionally more for the $\$ 3$ card than for the $\$ 70$ card.
} 
consumers to have both lower overall demands and steeper demand curves than dealers, consistent with what we find in the data.

In the subsections below, we discuss our two major results: (1) strategic behavior is much more evident for high-priced than low-priced cards, and (2) strategic behavior is more evident for dealers than for nondealers.

\section{A. Strategic behavior is evident primarily for high-priced cards}

Columns 3 and 4 of Table 2 provide strong evidence of strategic demand reduction. As the theory predicts, second-unit bids are lower in the uniform-price than in the Vickrey auctions. Mean Vickrey bids exceed mean uniform-price bids by approximately $\$ 12$ for the high-priced cards, and by only $\$ 0.05$ to $\$ 0.30$ for the lowpriced cards.

Figures 1-4 present a graphical depiction of these results. First, consider the data from auctions for \$70 cards: Ripken (nondealers) in Figure 1, and Sanders (nondealers) in Figure 2. In each case, we note that the distribution of uniform-price bids clearly lies to the left of the distribution of Vickrey bids, which we interpret as strategic demand reduction in the uniform-price auctions. In stark contrast are nondealers' second-unit bids on the $\$ 3$ cards: Jordan in Figure 3, and Montana in Figure 4. In these cases, the Vickrey and uniform-price bid distributions look nearly indistinguishable from each other, though the mean Vickrey bid remains numerically slightly higher than the mean uniform-price bid. ${ }^{8}$

\footnotetext{
${ }^{8}$ In the present paper, we provide figures only for second-unit bids. For histograms of first-unit bids, see List and Lucking-Reiley (2001).
} 
For each of the five different card treatments, we compute t-statistics for the hypothesis that mean second-unit bids are equal across auction formats: $\mathrm{t}_{\text {Sanders,ND }}=2.82$, $\mathrm{t}_{\text {Ripken, } \mathrm{D}}=3.10, \mathrm{t}_{\mathrm{Jordan}, \mathrm{D}}=0.47, \mathrm{t}_{\text {Montana, } \mathrm{D}}=1.19 ;_{\text {tMontana,ND }}=0.34 .{ }^{9}$ The five $\mathrm{t}$-statistics all have the expected positive sign, indicating that mean second-unit bids were larger in the Vickrey auctions than in the uniform-price auctions. ${ }^{10}$ However, the differences are statistically significant only for the two high-value cards (Ripken, Sanders), not for the low-value cards (Jordan, Montana).

We conclude that the demand-reduction effect appears larger when the stakes are higher. This is true not only in dollar magnitude, but also relative to the variance of bids (as measured by the t-test). Subjects may have considered the stakes in the $\$ 3$ card auctions not to be large enough to warrant careful consideration of strategies, and therefore made less than perfectly strategic second-unit bids. ${ }^{11}$ This is consistent with the previously cited literature on deliberation costs in laboratory experiments. ${ }^{12}$

\footnotetext{
${ }^{9}$ We report results of a large-sample test, which requires no distributional assumptions. We are making the large-sample assumption with sample sizes as small as 20; to check robustness we also conducted smallsample t-tests which assume populations have normal distributions and equal variances. The results were never qualitatively different.

${ }^{10}$ Further evidence of demand reduction can be obtained by examining the difference between each bidder's first and second-unit bids, a measure of the steepness of each bidder's downward-sloping bid schedule. In each case, the mean difference between first-unit and second-unit bids is much larger in the uniform-price than in the Vickrey auctions. For example, differences between bid one and bid two were \$7-\$23 in the Vickrey auctions for expensive cards, compared with \$30-\$45 in the uniform-price auctions. For the low-priced cards, bids differed by $\$ 0.80-\$ 0.90$ in the Vickrey auctions, and $\$ 1.00-\$ 1.50$ in the uniform-price auctions. But, we note that one caveat to this differencing approach is that we do not find equality of first-unit bids across auction formats (for high-priced cards). Instead, first-unit bids are larger in the uniform-price auctions than in the corresponding Vickrey auctions. The magnitude of the difference is in the $\$ 10$ neighborhood for the high-priced ( $\$ 70)$ cards, and $\$ 0.03$ to $\$ 0.46$ for the low-priced (\$3) cards. For further discussion of this anomaly, see List and Lucking-Reiley (2000).

${ }^{11}$ We implicitly assume here that the optimal strategy always involves demand reduction (lower secondbids in the uniform-price auction). Since the theoretically optimal strategy varies with the true distribution of bidder values, this is not necessarily the case. It is possible that because of intrinsic differences in bidder values, some cards should have more demand reduction than others in Nash equilibrium. The true values are not directly observable, but the Vickrey bids should provide a good indication of the true distribution of values.
} 


\section{B. Strategic behavior increases with experience}

We find some evidence for a second prediction of cognitive-cost theory: that strategic behavior is more pronounced when agents have more experience. Since dealers generally have more experience with auctions than nondealers, ${ }^{13}$ we examine differences in strategic behavior between dealers and nondealers. We focus here on bidding behavior for the $\$ 3$ Joe Montana card, the only card bid on by both dealers and nondealers.

The descriptive statistics in Table 2 indicate some evidence of dealers behaving more strategically than nondealers. The difference in mean second-unit bids between the Vickrey and uniform-price auctions is $\$ 0.32$ for dealers (roughly $25 \%$ of the mean Vickrey bid), but only $\$ 0.05$ for nondealers (roughly $10 \%$ of the mean Vickrey bid). Neither amount is significantly different from zero at conventional levels, but for dealers the difference at least begins to approach statistical significance ( $p=0.213$, two-tailed, versus $\mathrm{p}=0.734$ for nondealers).

\footnotetext{
Fortunately for our purposes, the main difference between the shapes of the low-stakes and the high-stakes value distributions is that the low-stakes cards appear to have values skewed towards zero. The theory generally predicts the opposite of what we observe: when values are more concentrated at zero, there should be more strategic demand reduction in uniform-price auctions. Although not proved in general, this claim is substantiated by several examples given by Engelbrecht-Wiggans and Kahn (1998) and Ausubel and Cramton (1996). The intuition for this claim (more demand reduction with lower distributions of values) is that the gains from demand reduction are greater when one's second-unit bid is more likely to actually determine the price, which can only occur when others' bids are sufficiently low. Thus, differences in bid distributions do not appear to be the reason for the observed lessening of demand reduction in our low-stakes experiments.
}

${ }^{12}$ See Slonim and Roth (1998) for a recent laboratory experiment where an increase in stakes moves behavior closer to Nash equilibrium. With a month's salary at stake instead of a more typical laboratory payoff amount, their subjects moved closer to subgame-perfect strategies in the ultimatum game, though the equilibrium was still significantly different from that predicted by theory.

${ }^{13}$ Admittedly, individuals in this market have little experience with multi-unit auctions, but we believe that previous experience with single-unit auctions may give bidders a better general feel for competitive bidding strategies. 
Figures 4 and 5 provide a visual comparison of the second-unit bids for the Joe Montana card. Figure 4 shows very little difference in mean bids between the two auction formats for nondealers, with somewhat higher variance of bids in the uniformprice auction. By contrast, Figure 5 shows one main difference in dealers' bidding behavior between auction formats: there are more zero bids in the uniform-price auction than in the Vickrey auction. A comparison between the two figures also indicates that the overall level of demand for the cards was higher for dealers, with a considerable number of bids above $\$ 2.00$, than for nondealers.

An alternative test of demand reduction provides stronger statistical support of the experience hypothesis. As in List and Lucking-Reiley (2000), we examine whether the slopes of individuals' bid schedules are steeper in the uniform-price auction than in the Vickrey auction. In other words, we test whether the difference between an individual's first-unit bid and his second-unit bid is greater in the uniform-price auction, as predicted by demand-reduction theory. Though dealers' bid schedules are slightly flatter than nondealers' bid schedules in the Vickrey auction (consistent with better resale opportunities for multiiple units), their bid schedules are somewhat steeper than those of nondealers in the uniform-price auction. Performing a two-tailed t-test of differences in bid differences across auction types, we find statistical significance at the $13 \%$ level $(\mathrm{p}=$ $0.128)$ for dealers, and statistical insignificance $(p=0.80)$ for nondealers. ${ }^{14}$ This evidence of a difference between dealers and nondealers, while somewhat noisy, is suggestive that dealers behave more strategically, exhibiting more demand reduction,

\footnotetext{
${ }^{14}$ See footnote 9 for a caveat to this finding.
} 
than nondealers. This finding is consistent with the notion that dealers need to exert less effort than nondealers to place optimal bids.

\section{Concluding Remarks}

Recent evidence from the laboratory indicates that predictions of rational models may fail if the cognitive costs of finding optimal strategies are large compared to their expected rewards. We explore this issue in the field by auctioning-off nearly $\$ 10,000$ worth of sportscards in 164 different auctions. Our results suggest that strategic behavior and expected payoffs are positively correlated. Indeed, bidders exhibited strategic demand-reduction behavior much more for high-priced cards than they did for lowerpriced cards. A second result is that subjects more experienced with sportscard auctions exhibited a greater tendency to engage in demand reduction than did less experienced subjects. The effect of the size of the stakes is much more pronounced than the effect of the bidder type. In particular, we find pronounced evidence of strategic behavior for goods worth around $\$ 70$. For goods worth around $\$ 3$, by contrast, we find no evidence of strategic behavior for inexperienced bidders (nondealers), and some weak evidence of strategic behavior for experienced bidders (dealers). The size of the stakes, and to some extent bidder experience, both help to explain when strategic behavior is more likely. 


\section{References}

Ausubel, Lawrence M. and Peter C. Cramton (1996), "Demand reduction and inefficiency in multi-unit auctions," University of Maryland, working paper.

Camerer, Colin and Robin M. Hogarth (1999), "The Effect of Financial Incentives on Performance in Experiments: A Review and Capital-Labor Theory," Journal of Risk and Uncertainty, 19, 7-42.

Clarke, E. (1971), “Multipart Pricing of Public Goods,” Public Choice, 2, 19-33.

Conlisk, John (1996), “Why Bounded Rationality?” Journal of Economic Literature, 34, 669-700.

Engelbrecht-Wiggans, Richard and Charles M. Kahn (1998), "Multi-Unit Auctions with Uniform Prices," Economic Theory, vol. 12, pp. 227-258.

Groves, Theodore (1973), “Incentives in Teams,” Econometrica, 41, 617-31.

Katzman, Brett Eric (1995), "Multi-unit auctions with incomplete information," Working paper, University of Miami.

List, John A. and Jason F. Shogren (1998), "Deadweight loss of Christmas: Comment," American Economic Review, December, 88(5), pp. 1350-1356.

List, John A. (2000), "Do Explicit Warnings Eliminate the Hypothetical Bias in Elicitation Procedures? Evidence from Field Auctions for Sportscards." American Economic Review, forthcoming.

List, John A., and David Lucking-Reiley (2000), "Demand Reduction in Multi-Unit Auctions: Evidence from a Sportscard Field Experiment," American Economic Review, forthcoming.

List, John A., and David Lucking-Reiley (2001), "Demand Reduction in Uniform-Price Multi-Unit Auctions," Handbook of Experimental Economic Results, forthcoming, 2001.

Noussair, Charles (1995), "Equilibria in a multi-object uniform price sealed bid auction with multi-unit demands," Economic Theory, 5, 337-351.

Slonim, Robert, and Alvin E Roth (1998), "Learning in high stakes ultimatum games: an experiment in the Slovak Republic," Econometrica, 66, 569-596.

Smith, Vernon L., and James M. Walker (1993), "Monetary Rewards and Decision Cost in Experimental Economics," Economic Inquiry, 31, 245-261. 
Smith, Vernon L., and Ferenc Szidarovszky (1999), "Monetary Rewards and Decision Cost in Strategic Interactions," Working paper, University of Arizona.

Tenorio, Rafael (1997), "On Strategic Quantity Bidding in Multiple Unit Auctions," Journal of Industrial Economics, vol. 40, no.2, pp. 207-217.

Vickrey, William (1961), "Counterspeculation, Auctions, and Competitive Sealed Tenders," Journal of Finance, vol. 16, no.1, pp. 8-37. 
Table 1. Experimental design.

\begin{tabular}{|c|c|c|c|c|c|}
\hline \multirow[b]{2}{*}{ Card Type } & \multirow[b]{2}{*}{$\begin{array}{l}\text { Book } \\
\text { Value }\end{array}$} & \multicolumn{2}{|c|}{ Non-Dealers } & \multicolumn{2}{|c|}{ Dealers } \\
\hline & & Uniform & Vickrey & Uniform & Vickrey \\
\hline $\begin{array}{l}\text { Barry Sanders } \\
1989 \text { Score }\end{array}$ & $\$ 70$ & 17 & 17 & --- & --- \\
\hline $\begin{array}{l}\text { Cal Ripken, Jr. } \\
1982 \text { Topps }\end{array}$ & $\$ 70$ & --- & --- & 15 & 15 \\
\hline $\begin{array}{l}\text { Michael Jordan } \\
1989 \text { Hoops }\end{array}$ & $\$ 3$ & 25 & 25 & --- & --- \\
\hline $\begin{array}{l}\text { Joe Montana } \\
1982 \text { Topps }\end{array}$ & $\$ 3$ & 15 & 15 & 10 & 10 \\
\hline
\end{tabular}

Notes:

1. Figures in cells represent the number of auctions run for each treatment type. For example, with 1989 Score Barry Sanders cards we ran 17 uniform-price auctions and 17 Vickrey auctions, with two cards each, for a total of 68 Barry Sanders cards sold.

2. Each auction had two invited bidders who submitted up to two bids each. 
Table 2. Descriptive statistics.

\begin{tabular}{lcccc} 
& \multicolumn{2}{c}{ Bid \#1 } & \multicolumn{2}{c}{ Bid \#2 } \\
& Vickrey & Uniform & Vickrey & Uniform \\
& & & & \\
Sanders (ND) & $\$ 51.82$ & $\$ 62.35$ & $\$ 28.82$ & $\$ 16.62$ \\
& 23.44 & 25.67 & 19.98 & 15.40 \\
& & & & \\
Ripken (D) & 49.60 & 62.67 & 41.77 & 30.60 \\
& 15.19 & 15.28 & 14.46 & 13.43 \\
& & & & \\
Jordan (ND) & 1.73 & 1.83 & 0.91 & 0.82 \\
& 1.51 & 1.35 & 1.04 & 0.85 \\
Montana (D) & 2.03 & 2.49 & 1.26 & 0.94 \\
& 0.86 & 2.18 & 0.84 & 0.85 \\
& & & & \\
Montana (ND) & 1.37 & 1.40 & 0.47 & 0.42 \\
& 1.33 & 1.44 & 0.53 & 0.61
\end{tabular}

Notes:

1. Means are in plain text, while standard deviations are in italics.

2. (ND) denotes nondealer treatment, while (D) denotes dealer treatment.

3. Bid \#1 data consists of the first bid submitted by each bidder. Bid \#2 data consists of the second bid submitted by each bidder. 
Figure 1. Second-unit bids on Ripken ( $\$ 70$ book value) by dealers

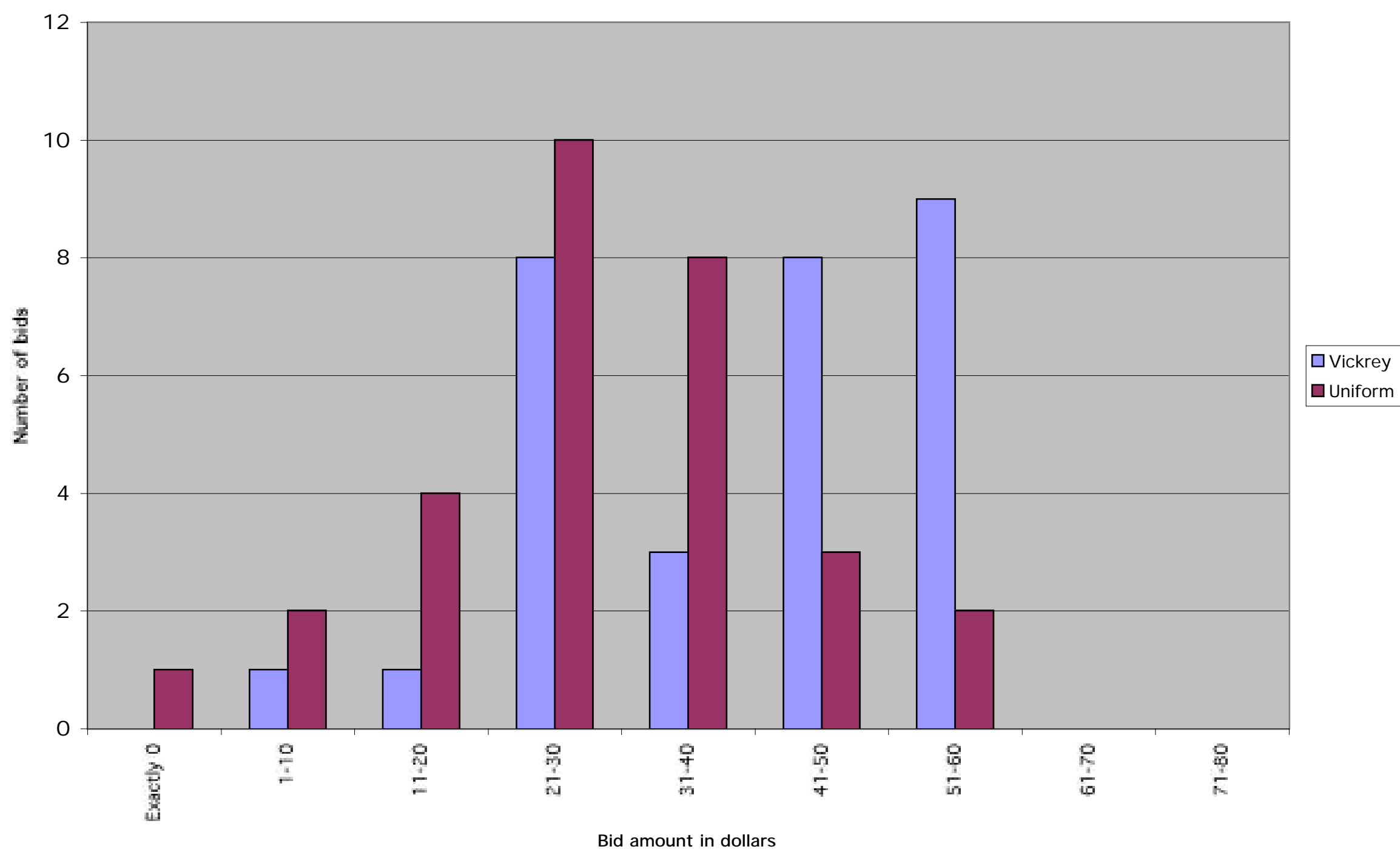


Figure 2. Second-unit bids on Sanders ( $\$ 70$ book value) by nondealers

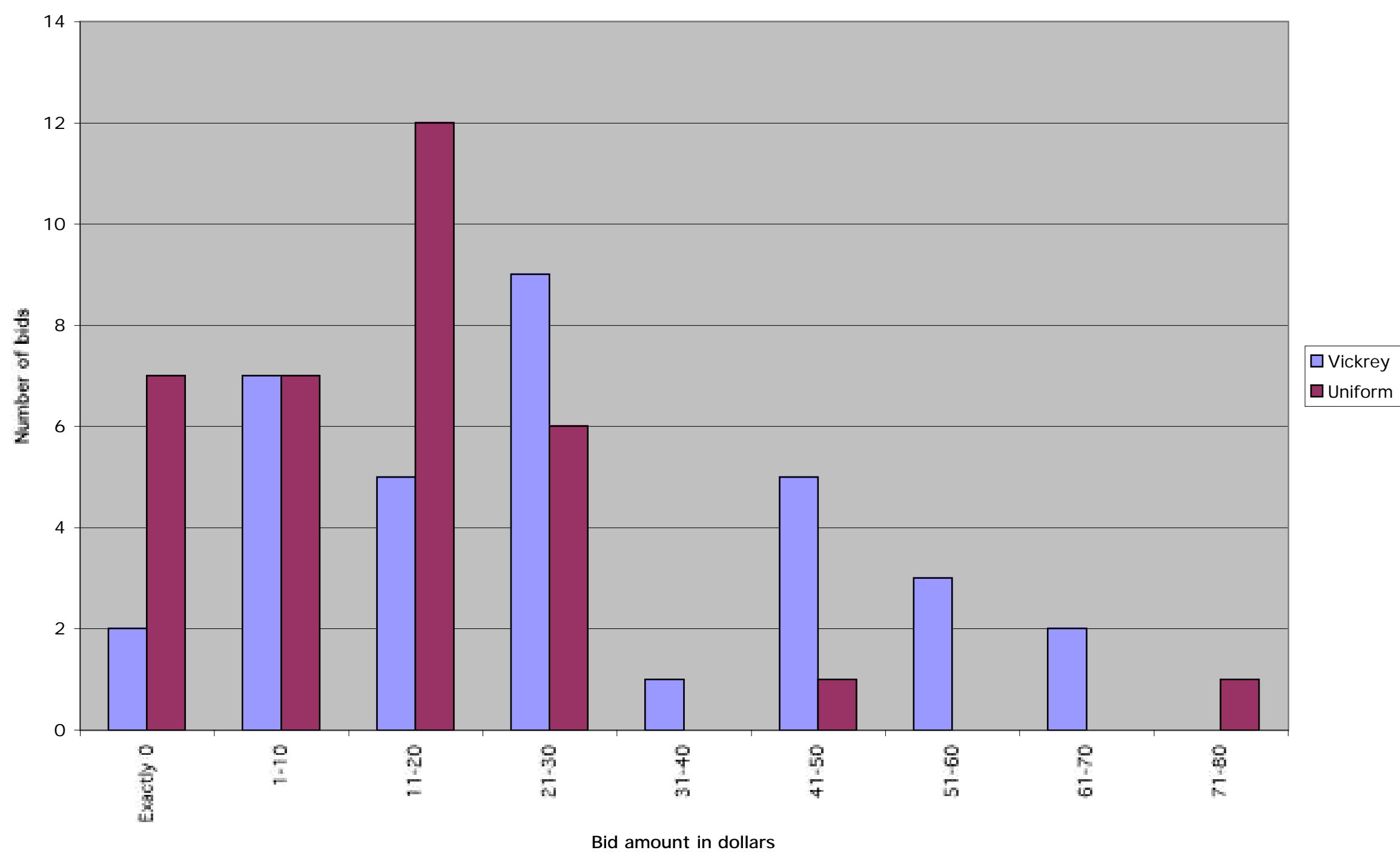


Figure 3. Second-unit bids on J ordan ( $\$ 3$ book value) by nondealers

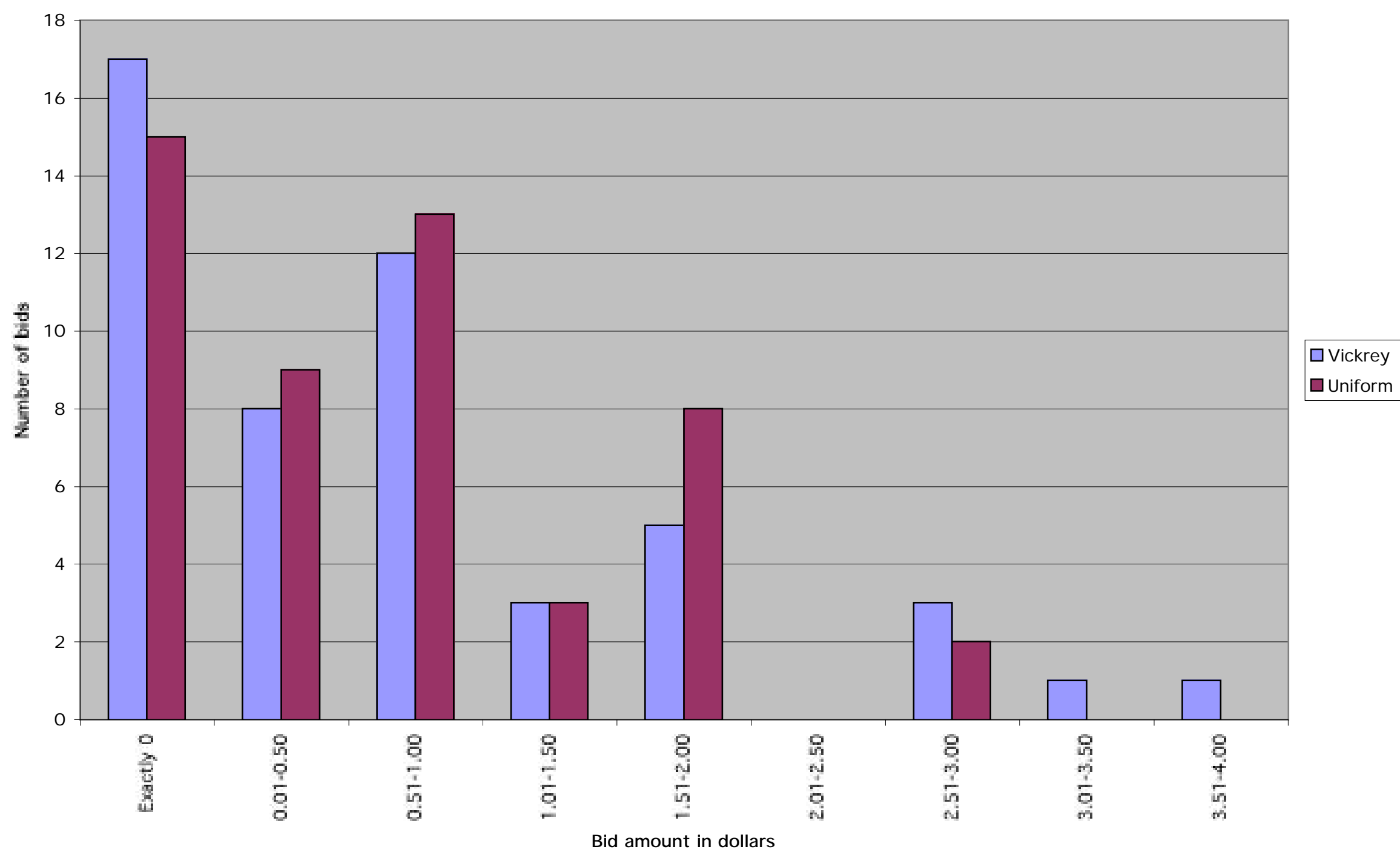


Figure 4. Second-unit bids on Montana ( $\$ 3$ book value) by nondealers

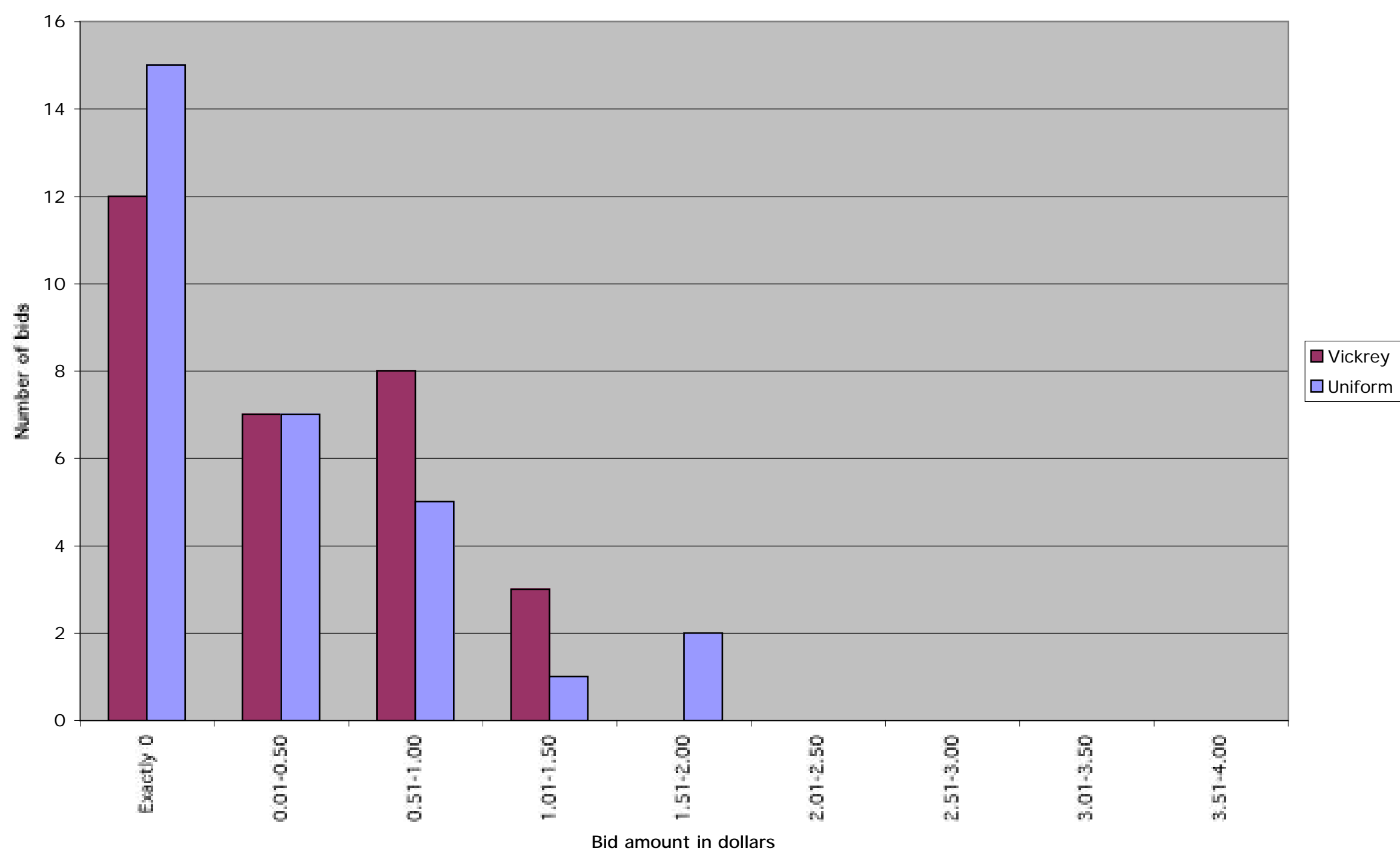


Figure 5. Second-unit bids on Montana ( $\$ 3$ book value) by dealers

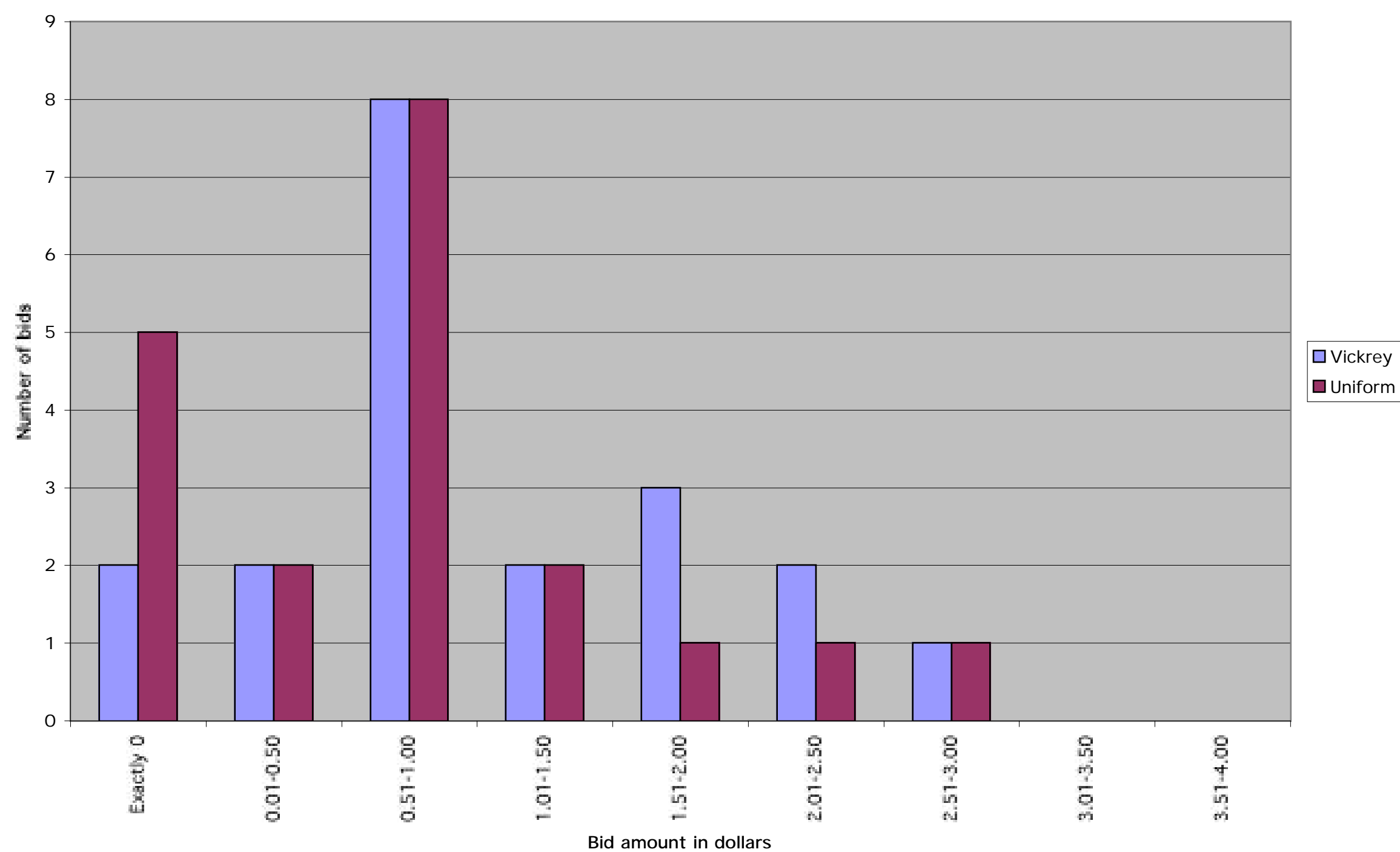




\section{Appendix 1. Subject Instructions for Uniform-Price Auction}

Welcome to Lister's Auctions. You have the opportunity to bid in an auction for two identical sportscards. There are only two bidders in this auction; the other bidder will be randomly chosen from other participants at today's card show. (If you are a card dealer you will be paired randomly with one other card dealer in your auction. If you are a non-dealer, you will be paired with one other non-dealer.)

The cards up for auction are two copies of the following card: Card A PSA 8

\section{Auction Rules:}

You are asked to submit two bids - one bid for each card. If you choose to place only one bid, your second bid will be counted as a bid of zero dollars.

Since there are two bidders, there will be a total of four bids submitted. The winning bids will be the highest two from the group of four bids. For each card won, the purchase price is equal to the amount of the third-highest bid (that is, the highest losing bid).

I will order the four bids from highest to lowest in order to determine the winners of the two items.

For example, if the bids are ranked highest to lowest as follows:
$\$ \mathrm{~A}$
$\$ B$
$\$ C$
$\$ \mathrm{D}$

The bidder who bid $\mathbf{\$ A}$ wins one card and pays $\mathbf{\$ C}$.

The bidder who bid $\mathbf{\$ B}$ wins the second card and pays $\mathbf{\$ C}$.

Note that one person might have submitted both of the top bids, and thus would buy both cards for \$C each.

If a TIE occurs between $\$ \mathrm{~B}$ and $\$ \mathrm{C}$, I will flip a coin to determine the winner.

\section{Example}

Before you submit your actual bids, I would like you to work through an example. Consider a couple of bids that you might submit, and write the numbers here in these two blanks.

my 1 st bid

my 2nd bid

Now make up a couple of bids that the other bidder might submit, and fill those numbers into these blanks.

other bidder's 1st bid

other bidder's 2nd bid 
Take the four bids and order them from highest to lowest:

highest bid:

lowest bid:

Now, determine how many cards you have won, how many cards the other bidder has won, and the amount each of you has to pay. Fill those numbers in here.

number of cards I won

amount I must pay

number cards other bidder won

amount other bidder must pay

To assure that you understand how this auction mechanism operates, I will check your work after you complete this example.

\section{Final Transaction}

At 1PM I will determine the winners of each auction completed between 8AM and 12:30PM. For those auctions completed after 1PM I will determine the winners at 5PM. After the winners pay me (cash or check) for the cards, the cards will be awarded to the winners. Note, regardless of price, the cards will be awarded to the winners. In case you cannot attend the "determination of winners" sessions, please provide your name, mailing address, and phone number below:

Name

Address

Phone\#

If you are unable to attend at 1PM (or 5PM), I will contact you by phone. Upon receipt of your check or cash, I will send you the cards that you won. All postage will be paid by Lister's Auctions for cards mailed to winners.

Note that while this is a real auction for real cards, I plan to use data on the bids in this auction for economic research. I guarantee to sell both of the cards listed to the winners of this two-bidder auction, no matter what the final auction prices turn out to be. Your bids represent binding commitments to buy cards you win at the prices specified by the auction outcomes.

Good luck—please write your bids on the sheets provided.

Thanks for participating. 


\section{Appendix 2. Subject Instructions for Vickrey Auction}

All text is identical to that of Appendix 1, with the exception of the Auction Rules and Example sections, shown below:

\section{Auction Rules:}

You are asked to submit two bids - one bid for each card. If you choose to place only one bid, your second bid will be counted as a bid of zero dollars.

Since there are two bidders, there will be a total of four bids submitted. The winning bids will be the highest two from the group of four bids. For each card won, the purchase price will be determined as follows.

$<$ For the first unit you win, you pay an amount equal to the highest rejected bid which was not your own.

$<$ For the second unit you win, you pay an amount equal to the second-highest rejected bid which was not your own.

I will order the four bids from highest to lowest in order to determine the winners of the two items.

Example 1: if the bids are ranked highest to lowest as follows:

$\begin{array}{ll}\text { \$A } & \text { (from bidder 1) } \\ \text { \$B } & \text { (from bidder 2) } \\ \text { \$C } & \text { (from bidder 2) } \\ \text { \$D } & \text { (from bidder 1) }\end{array}$

Bidder 1 wins one card and pays $\mathbf{\$ C}$. Bidder 2 wins the second card and pays \$D.

Example \#2. If bids are rank ordered as follows:

$\begin{array}{ll}\text { \$A } & \text { (from bidder 1) } \\ \text { \$B } & \text { (from bidder 1) } \\ \text { \$C } & \text { (from bidder 2) } \\ \text { \$D } & \text { (from bidder 2) }\end{array}$

Bidder 1 wins one card and pays \$C. Bidder 1 wins the second card and pays \$D.

Example \#3. If bids are rank ordered as follows:
\$A (from bidder 1)
\$B (from bidder 2)
$\$ \mathrm{C} \quad$ (from bidder 1)
\$D (from bidder 2)

Bidder 1 wins one card and pays \$D. Bidder 2 wins the second card and pays \$C. If a TIE occurs between $\$ \mathrm{~B}$ and $\$ \mathrm{C}$, I will flip a coin to determine the winner. 


\section{Example}

Before you submit your actual bids, I would like you to work through an example. Consider a couple of bids that you might submit, and write the numbers here in these two blanks.

my 1 st bid

my 2nd bid

Now make up a couple of bids that the other bidder might submit, and fill those numbers into these blanks.
other bidder's 1st bid
other bidder's 2nd bid

Take the four bids and order them from highest to lowest:

highest bid:
$-$
lowest bid:

Now, determine how many cards you have won, how many cards the other bidder has won, and the amount each of you has to pay. Fill those numbers in here.

number of cards I won

amount I must pay

number cards other bidder won

amount other bidder must pay

To assure that you understand how this auction mechanism operates, I will check your work after you complete this example. 